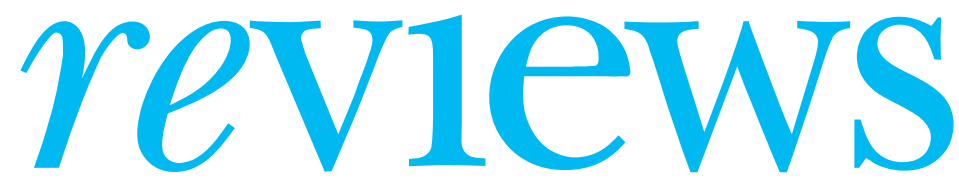

BOOKS • CD ROMS • ART •WEBSITES $\bullet$ MEDIA $\bullet$ PERSONAL VIEWS $\bullet$ SOUNDINGS

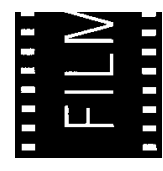

\section{The Day After Tomorrow}

Directed by Roland Emmerich

On general release worldwide from 28 May 2004

\section{Rating: $\star \star \star$}

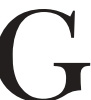

lobal warming gets the Hollywood treatment in The Day After Tomorrow, a disaster movie where the threat to humanity comes from nature itself as a result of changes in the world's climate. In Roland Emmerich's film extreme weather events induced by human activity lash down on the northern hemisphere, with devastating consequences. The resonance of the scenario is heightened by some breathtaking special effects and by the claim that it could one day happen-but how real is the science behind all this?

The premise stems from the fact that rapid melting of polar ice, brought about by global warming, could alter the flow of ocean currents. The United Kingdom, for example, is partly warmed by the Gulf stream, a current of warm water that flows from the Gulf of Mexico past the western shores of Britain. Once this stream reaches the Arctic, the water at the surface of the sea becomes cooler and denser because of bitter winds and then sinks to the bottom of the ocean and flows back south. This creates a conveyor belt effect as water is regularly circulated; but an increase in fresh water from melting ice at the polar caps could desalinate the water to such an extent that a

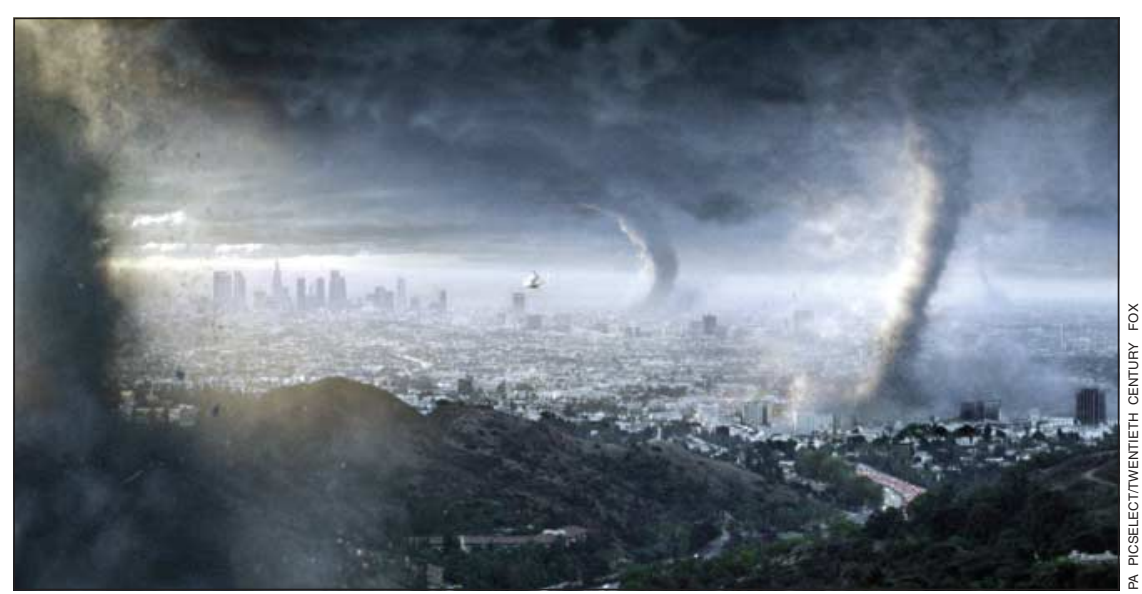

The Day After Tomorrow was reported to be a "carbon neutral" production

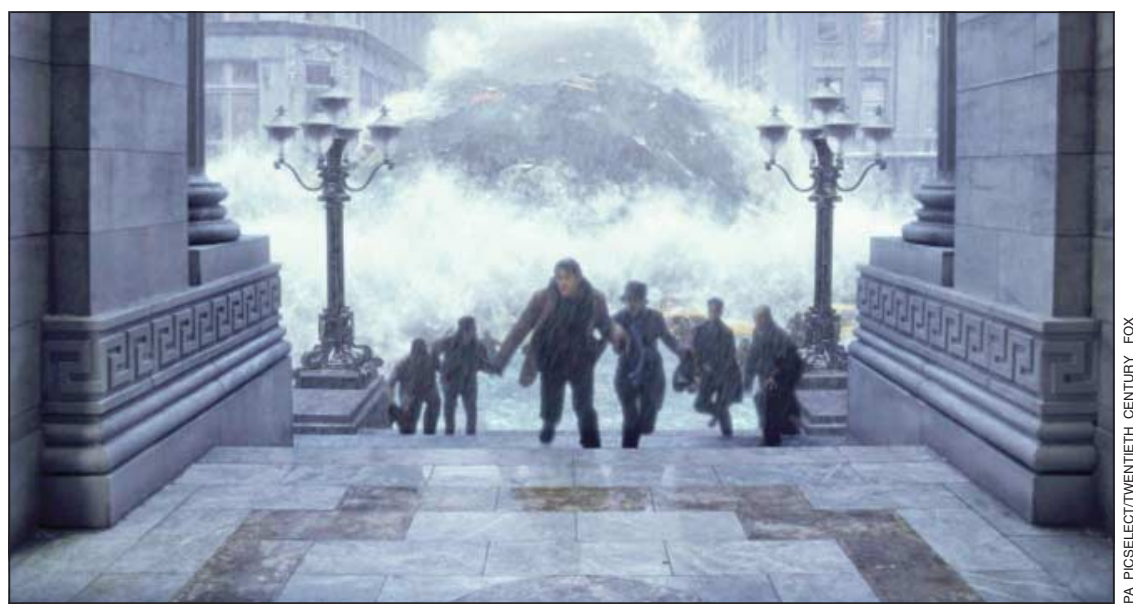

Taken by storm: but how real is the science behind the film? slowing down or even switching off of the Gulf stream could occur. If it did, it has been proposed that the United Kingdom's average temperature could fall by up to $5^{\circ} \mathrm{C}$, and it could happen quickly-in a matter of a decade or two.

However, climate simulations run by the Research show that although the Gulf stream could indeed slow down-by about $20 \%$ by the middle of the century-if carbon dioxide is emitted in ever increasing quantities, it would be unlikely to switch off completely. So the scenario of another ice age is an unlikely one, but we still need a better understanding of the earth's climate system for any predictions to be more robust.

The Day After Tomorrow presents the worst case scenario, with New York suffering in just six days the kind of weather related disasters that could be expected over 100 Hadley Centre for Climate Prediction and

years of the most severe climate change. What happens to the rest of the world is somewhat glossed over, with the British contingent at the Hedland Centre (a nod to Hadley?) succumbing gracefully and so quickly that not even the gritters could be held responsible. What was welcome in the film, however, was the political comment that rich countries would have to drop the debt owed to them by poorer countries in order for their citizens to gain entry as environmental refugees fleeing south to escape the cold. Also, the movie does, to its credit, realistically portray the US administration as being very sceptical towards the scientific theories put forward by Dennis Quaid's climatologist character. The US economy is more fragile than the climate, announces the US vice president at a delegation in a snow covered New Delhi.

Interestingly, the movie was reported to be a carbon neutral production: any carbon emissions entering the atmosphere as a direct result of the making of the film, and thereby contributing to global warming, were offset by actions to help compensate for those emissions, such as planting trees and using "green" energy. This claim suggests that the production team was aware of the movie's scientific and political message. The threat of global warming is real, the exact consequences and timescales proposed in The Day After Tomorrow may not be, but this entertaining Hollywood blockbuster does no harm in raising awareness of a serious issue.

Shakoor Hajat lecturer, Public and Environmental Health Research Unit, London School of Hygiene and Tropical Medicine

Shakoor.Hajat@lshtm.ac.uk 


\section{Climate Change and}

\section{Human Health: Risks and Responses}

Eds A J McMichael, D H Campbell-Lendrum, C F Corvalán, K L Ebi, A K Githeko, J D Scheraga, A Woodward

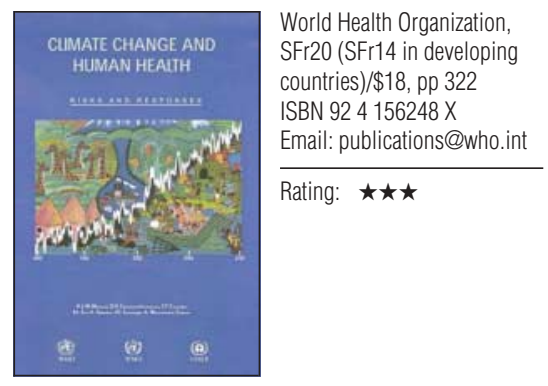

$\mathrm{T}$ he UK government's chief scientist, David King, has said that "climate change is the most severe problem we are facing today-more serious even than the threat of terrorism." Yet terrorism continues to dominate the world's news media and preoccupy the thoughts of many people. James Wolfensohn, president of the World Bank, recently told an audience of representatives of business and civil society groups that the environment was on the back burner of international discussions on development.

It is perhaps time to be reminded of Hippocrates, suggests Tony McMichael, one of the editors of Climate Change and Human Health. Hippocrates related epidemics to seasonal changes in weather, writing that physicians should have "due regard to the seasons of the year, and the diseases which they produce, and to the states of wind peculiar to each country and the qualities of its waters."

The central tenet of this book is that we must rapidly reacquaint ourselves with global environmental systems and how we depend on them. The long term good health of populations depends on the continuing stability and functioning of the biosphere's ecological and physical systems. The book is a timely reminder that the debate on global warming is shifting from a "will it or won't it happen" question to a recognition that some effect is inevitable. Even if substantial reductions in greenhouse emissions were to be made the planet would continue to warm for at least the next 50 years and sea levels continue to rise for hundreds of years, because of the time it takes for basic global systems to reach a new equilibrium. Now we urgently need to understand what the likely impacts of climate change will be and which populations are most at risk, so that global society can respond appropriately.

It is clear from the efforts of meteorological scientists, epidemiologists, and others reflected in this book that the likely impact on health of climate change is a hugely complicated and uncertain business. Much of the evidence presented is based on the third assessment report of the International Panel on Climate Change, which reported in 2001. Important influences on health will include extreme weather, changes in the transmission of infectious diseases, food production, air pollution, population displacement, and civil strife.

The people who will be hit first and hardest by climate change are, by and large, already among the poorest on the planet. For example, the panel concluded with "medium confidence" that, because of the effects on crop yields, climate change will increase the number of hungry and malnourished people in the 21 st century by 80 or 90 million. The consequences of extreme weather differ vastly, according to populations' ability to cope. For example, cyclones in Bangladesh in 1970 and 1991 caused an estimated 300000 and 139000 deaths, respectively. In contrast Hurricane Andrew caused 55 deaths when it struck the United States in 1992.

Clearly, the world's poorest people are also the least able to adapt to climate change. An equitable agenda for climate change is also an agenda for development that has as a top priority the reduction of socioeconomic vulnerability.

This book has a long shopping list, much focused on research and data needs. However, the authors call clearly for adoption of the precautionary principle whereby policy makers do not wait for all the data to be in before acting to limit adverse impacts. Excellent though this book is, do not expect to be provided with a menu of actions. Although it sets out some guiding principles the difficult choices that must now be made and the "missing action" are down to all of us.

Cathy Read consultant in public health, Barnsley Primary Care Trust

\section{Working with Dangerous People: The Psychotherapy of Violence}

Ed David Jones

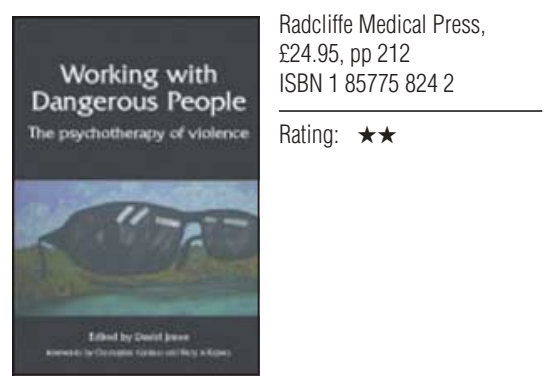

I read this book on a recent trip to New York. On a beautiful spring day in Manhattan's upper east side, it is hard to believe that the annual rate of homicide in the city is the same as the annual rate for the whole of England and Wales. It doesn't take a minute in New York to work out that reducing violence is an urgent political priority; so a book about an unusual approach to treating violent men should be of interest.

Unlike the more structured programmes of cognitive behaviour group therapy that form the mainstay of psychological treatment in prison, Grendon Prison, outside Aylesbury, Buckinghamshire, offers unstructured groups, drawing on a therapeutic community model. Perhaps the main difference between the two approaches is that cognitive behaviour group therapy focuses on the conscious experience of beliefs, attitudes, and choices related to violence, while the community model focuses on unconscious experience.

Grendon's therapeutic community model has been in existence for over 40 years, and extended feedback about the prison's work is welcome. This is particularly true at a time when some of the optimism about the efficacy of cognitive behaviour programmes is beginning to diminish, especially for prisoners with more entrenched and severe psychological difficulties. The book has two particularly good chapters, one by Agnes Petocz and the other by Richard Shuker, about the validity of both models and ways of researching them; but the overall message is that both models aim to help an offender to change how he thinks about violence, using trained professionals who carry out carefully thought out interventions under supervision. Although there is a fine old tradition of squabbling between theoretical schools in psychology, the reality is that the approaches are more alike than they are different.

For professionals working in the field, I would say this book is worth buying for $\mathrm{Liz}$ McLure's chapter alone, a powerful and poignant description of being a therapist in Grendon. But the addicts of evidence based medicine will now be asking the important question: does the Grendon approach work? Does it help convicted offenders not to reoffend? The research to date indicates that it does, especially if prisoners stay long enough in treatment (which suggests an interesting dose-response effect). The figures that impressed me were those showing that seriously violent men, with histories of rule breaking and bad behaviour in other prisons, markedly reduce such behaviour when they come to Grendon; and that overall the rate of rule breaking in Grendon is lower than in other prisons. It seems that something is working in Grendonsomething that makes some of the most disordered men in the country stop and think before acting violently. As they say in New York, "Go figure."

Gwen Adshead consultant forensic psychiatrist, Broadmoor Hospital, Berkshire

Gwen.adshead@wlmht.nhs.uk 
PERSONAL VIEW

\section{I don't like Mondays (after bank holidays)}

$\mathrm{A}^{\mathrm{n}}$ lthough everyone, to some extent, lives their life according to the days of the week, this phenomenon is perhaps most noticeable in the NHS. If it's Tuesday, it must be theatre/clinic/ward round. This is never so clear as in spring, when each hospital in the United Kingdom has to cancel a disproportionate number of activities scheduled for a Monday because of three bank holidays (Easter, May Day, Whitsun) occurring within a couple of months.

Anyone who has come into contact with the NHS Modernisation Agency recently will know that it has identified one of the biggest problems leading to prolonged waiting times as a mismatch of capacity and demand. Although this is usually applied to computed tomography, outpatient clinics, etc, it strikes me that there is a capacity and demand mismatch across the whole NHS, caused by the fact that bank

minimise the mismatch. I wonder if it might be possible to improve the situation by designating a couple of midweek days in April or May as "NHS Mondays," when the entire NHS would function as if it were a Monday, even though it is really a Tuesday or Wednesday. This would help alleviate the current imbalance.

This idea has been aired at various levels in the Department of Health, and although some people have responded by saying that perhaps we should not observe bank holidays in the NHS (ideal but unworkable, I think), I have had encouragement from others. However, it has been suggested that initially I should try to make this work as a pilot study at a local level.

Unfortunately trying to alter weekly timetables in one small part
The NHS is highly

dependent on days of the week of the NHS is difficult. For example, in my specialtyoncology-although I work for one trust primarily, our cancer network is such that we also provide a service to holidays are unevenly distributed across the working week. The NHS is highly dependent on days of the week, and almost all hospitals, GP surgeries, and other clinical units are timetabled differently for each working day between Monday and Friday.

In 2004 there are five bank holiday Mondays, but only one holiday Friday (Good Friday), one holiday Thursday (New Year's Day), and one holiday Tuesday (Boxing Day). There are no bank holidays on a Wednesday this year. This means that the capacity of clinics and operating sessions scheduled on a Monday is almost 10\% lower than those on other days of the week. The situation is even more acute in April and May when three out of eight Mondays are public holidays, which means a net loss in capacity of clinical activities of $37.5 \%$, or, for someone like me who does fortnightly new patient clinics in peripheral hospitals, even as much as $50 \%$

Principles of capacity and demand planning would suggest that we need to

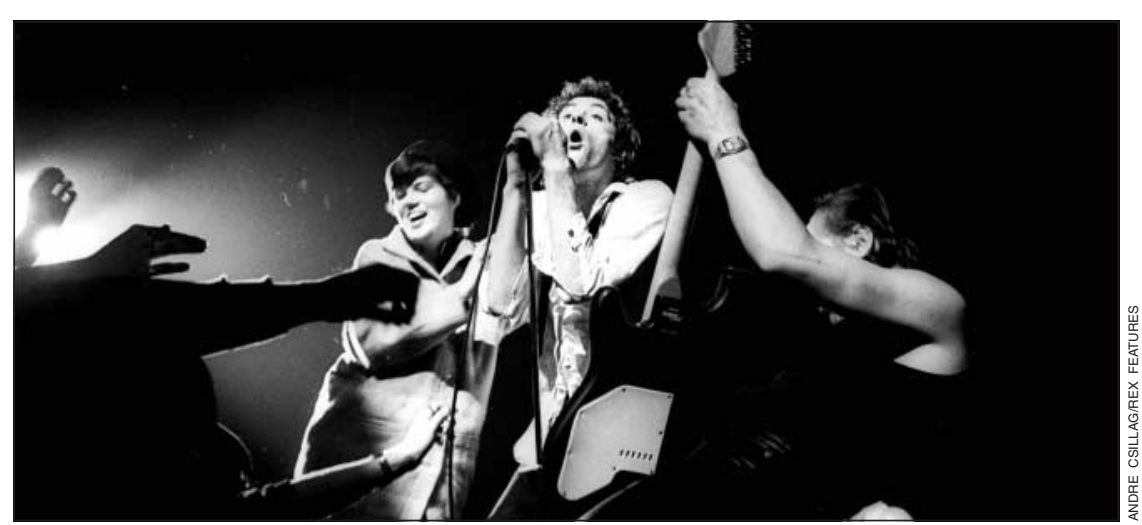

four other different trusts. For this pilot to work in oncology, all five would need to sign up. However, the cancer network is different to all the other formal and/or informal networks that exist, and it seems to me that it would not be possible to enact this without the entire country signing up.

This may be almost as infeasible as asking everybody to work Easter Monday, and I am sure there would be practical difficulties involved, especially with on-call rotas and part time workers. Nevertheless it might have significant benefits. It might also abolish those "heartsink Mondays" that immediately follow a bank holiday, when everything is overbooked, and patients and staff become increasingly exasperated. Depressingly, in April and May, it is inevitable that the whole process will repeat itself a few weeks later.

Peter Kirkbride clinical director, radiation services, Weston Park Hospital, Sheffield peterkirkbride@sth.nhs.uk

We don't like Mondays either, sang punk band the Boomtown Rats
SOUNDINGS

\section{Of evolution and homosexuality}

Except for the Pope and President Bush, and their respective phalanxes, everyone including the $B M J$, is eager to proclaim that homosexuality is not an aberration. So far no one seems to have recognised its evolutionary role.

The survival value of homosexuality for the human species is to be found in its effect on population growth. Anyone who is worried about environmental degradation caused by the growth of the human population should promote homosexuality. Indeed, it would be desirable if most people became homosexual and only a small, selected proportion of humans of every recognisable subgroup attended to the modest reproductive needs of the species.

All the effort, emotion, and money spent on family planning could be saved, and disgusting and unnatural practices of contraception-such as genital mutilation, various prophylactic methods, and even withdrawal and the observance of cervical mucus-could be done away with. Indeed, homosexual sex is akin to organic farming inasmuch as it eschews artifice, yet it yields pleasure and elation and, often, pure love.

The ideal social organisation of mankind in this overcrowded world would be one in which the majority lived in homosexual monogamy. If homosexuality became the norm, population numbers would decline precipitously.

From the point of view of the species, the survival value of this arrangement is obvious. The concept of cultural evolution can explain how the paradigm leap came about, for so far "natural" evolution has been known to work only through the machinery of reproduction and not its negation. Avoiding reproduction is a cultural activity par excellence.

As far as recruitment into the breeding groups is concerned, in the immediate future there will be no shortage of volunteers. But eventually, as the breeders will become a minority, there is the danger that they will be discriminated against. Protection of "aberrant" behaviour such as reproduction will be just as much in the interest of the species as is now the upholding of homosexual rights for the sake of reversing population growth.

Prejudice against homosexual marriage will diminish as soon as people realise that that newly established institution is a guarantor of "natural" population policy.

Imre Loefler editor, Nairobi Hospital Proceedings, Kenya 